\title{
Lower-limb endurance training program influences thoracoabdominal motion of patients with COPD?
}

\author{
Um programa de treinamento de endurance influencia o \\ movimento toracoabdominal de pacientes com DPOC?
}

\section{Danielle Corrêa França ${ }^{[a]}$, Danielle Soares Rocha Vieira ${ }^{[b]}$, Bruna da Silva Pinto Pinheiro Vieira ${ }^{[c]}$, Trícia Guerra e Oliveira ${ }^{[\mathrm{d}]}$, Raquel Rodrigues Britto ${ }^{[\mathrm{e}]}$,Verônica Franco Parreira ${ }^{[\mathrm{f}]}$}

[a] Ph.D. student, Sciences Rehabilitation Program, Federal University of Minas Gerais, Belo Horizonte, MG - Brazil, e-mail: daniellecf2005@yahoo.com.br

[b] Professor, Department of Physical Therapy, Federal University of Minas Gerais, Belo Horizonte, MG - Brazil, e-mail: danisrvieira@yahoo.com.br

[c] Undergraduate student, Department of Physical Therapy, Federal University of Minas Gerais, Belo Horizonte, MG - Brazil, e-mail: vieirabruna@hotmail.com

[d] Professor, Department of Physical Therapy of Vila Velha University, Vila Velha, ES - Brazil, e-mail: triciagm@ig.com.br

[e] Full Professor, Department of Physical Therapy, Federal University of Minas Gerais, Belo Horizonte, MG - Brazil, e-mail: rbrito@ufmg.br

[f] Full Professor, Department of Physical Therapy, Federal University of Minas Gerais, Belo Horizonte, MG - Brasil, e-mail:veronicaparreira@yahoo.com.br

\section{Abstract}

Introduction: Thoracoabdominal-TA asynchrony is an important sign of Chronic Obstructive Pulmonary Disease (COPD). Studies investigating the influence of endurance training on TA asynchrony have not been found. Objective: To analyze lower-limb endurance training effects on TA asynchrony in patients with COPD. Materials and methods: Two patients with severe COPD were evaluated in a single-subject design $\mathrm{AB}$ (A-baseline for six weeks, B-training on cycle ergometer with intensity of $70 \%$ of baseline peak load, for 12 weeks) with repeated measures of variables: phase inspiratory relation (PhRIB), phase expiratory relation (PhREB) and phase angle ( $\mathrm{PhAng}$ ). These variables were assessed by respiratory inductive plethysmography during incremental exercise tests on a cycle ergometer (same load and peak load of each test). Statistical methods included visual analysis, two-standard deviation band test and split middle line test, considering significant $\mathrm{p}<0.05$. It was considered the results for variables with agreement of at least two 
analyses. Data are presented as mean \pm SD for phases A and B. Results: During phase B, Patient 1 presented significant decrease of PhRIB (22.7 $\pm 3.4 \times 17.0 \pm 4.9)$ and PhAng (16.5 $\pm 5.1 \times 13.2 \pm 2.1)$ for same load and PhREB (16.8 $\pm 3.1 \times 13.3 \pm 3.1)$ and PhAng $(23.4 \pm 1.7 \times 20.1 \pm 2.3)$ at peak load. Patient 2 showed significant decrease of PhRIB for same load and (14.4 $\pm 3.8 \times 13.9 \pm 3.9)$ at peak load (19.1 $\pm 2.5 \times 15.7 \pm 2.7)$. Conclusions: These results suggest that lower-limb endurance training reduced TA asynchrony in patients with severe COPD. The findings may be related, according to the literature, to the lower ventilatory demand and greater exercise capacity of patients with COPD undergoing endurance training.

Keywords: Rehabilitation. Physiotherapy. Physical exercise. Chronic obstructive pulmonary disease.

\section{Resumo}

Introdução: A assincronia toracoabdominal (TA) é um importante sinal da Doença Pulmonar Obstrutiva Crônica (DPOC). Estudos investigando a influência do treinamento de endurance sobre assincronia TA não foram encontrados. Objetivo: Analisar as repercussões do treinamento de endurance dos membros inferiores-MMI sobre a assincronia TA em indivíduos com DPOC. Materiais e métodos: Dois pacientes com DPOC grave foram avaliados em um estudo experimental de caso único $A B$ (A-baseline por seis semanas, $B$-treinamento em cicloergômetro com intensidade de 70\% da carga pico atingida no baseline, por 12 semanas) com medidas repetidas das variáveis: relação da fase inspiratória (PhRIB), relação da fase expiratória (PhREB) e ângulo de fase (PhAng). Essas variáveis foram analisadas pela pletismografia respiratória por indutância durante testes de exercício incremental em cicloergômetro (isocarga e carga pico em cada teste). Os métodos estatísticos incluíram análise visual, two-standard deviation band e split middle line test, considerando significativo $p<0,05$. Foram considerados os resultados com concordância de pelo menos duas análises. Resultados: Durante a fase $B$, o paciente 1 apresentou redução significativa da PhRIB $(22,7 \pm 3,4 \times 17,0 \pm 4,9)$ e PhAng $(16,5 \pm 5,1 \times 13,2 \pm 2,1)$ para isocarga e PhREB $(16,8 \pm 3.1 \times 13,3$ $\pm 3,1)$ e PhAng $(23,4 \pm 1,7 \times 20,1 \pm 2,3)$ na carga pico. O paciente 2 mostrou redução significativa do PhRIB para isocarga $(14,4 \pm 3,8 \times 13,9 \pm 3,9)$ e na carga pico $(23,4 \pm 1,7 \times 20,1 \pm 2,3)$. Conclusões: Os resultados sugerem que $o$ treinamento de resistência dos MMII reduziu a assincronia TA nos pacientes avaliados. Os resultados podem estar relacionados, de acordo com a literatura, com a menor demanda ventilatória e maior capacidade de exercício dos pacientes submetidos a um treinamento de endurance.

Palavras-chave: Reabilitação. Fisioterapia. Exercícios físicos. Doença pulmonar obstrutiva crônica.

\section{Introduction}

An important sign of COPD, related to disease severity, is the presence of asynchronous thoracoabdominal motion (TAM) during the respiratory cycle (1-4). Asynchronous TAM can be described in two categories: asynchrony, which reflects the delay between thoracic and abdominal compartments in expansion or retraction and paradoxical movement which consists of opposite movement between rib cage $(\mathrm{RC})$ and abdomen $(\mathrm{AB})$, also reported as complete asynchrony $(5,6)$.

Several studies have assessed TAM in patients with COPD (1-3, 5, 7-10). According to the literature, these patients present more thoracoabdominal asynchrony compared to healthy subjects, both at rest (5, 8) and during exercise (9). Exercise may reinforce the asynchrony in patients with COPD $(7,9)$, and the presence of asynchronous TAM in these patients was associated with higher severity of the disease, increased risk of respiratory failure and worse prognosis (1-3). However, in most of the studies objective measurements were not used (1-3, 9).

Another disturbing sign of COPD is the intolerance to exercise (11). One of the primary symptoms that limits the exercise in patients with COPD is dyspnea $(11,12)$, which can be related to the dynamic hyperinflation $(4,12-15)$.

Dyspnea and exercise capacity limitation form a "vicious circle" with social and psychosocial consequences for these patients. Pulmonary rehabilitation can interrupt this circle since that the lower-limb endurance training can provide important positive effects in patients with COPD (16-21). However, studies 
addressing the influence of lower-limb endurance training on thoracoabdominal asynchrony of patients with COPD have not been found.

\section{Materials and methods}

It was conducted a single-subject experimental design $\mathrm{AB}$ aiming at documenting lower-limb endurance training effects on TA asynchrony in patients with COPD. The study consisted of weekly assessments for six weeks (Phase A) followed by lower-limb endurance training for 12 weeks with evaluations every 15 days (Phase B). The University Ethics Research Committee approved the protocol and the subjects gave informed consent.

\section{Subjects}

Two patients with severe COPD (4), negative results on bronchodilator tests (22), clinical stability, aged 73 (participant 1) and 64 (participant 2) years old, normal body mass index (BMI), former smokers, without cardiac and metabolic diseases and not performing physical exercise on a regular basis.

\section{Assessment}

Patients underwent a maximal incremental symptom-limited exercise test on cycle ergometer (Ergo Cycle167, Pirmasens, Germany) consisting of: 1) three minutes resting, 2) one minute cycling at the basal bicycle work load (15 watts), 3) 10-watt increments per minute until exhaustion or occurrence of any exercise interruption criterions (23), 4) three minutes cycling at the basal work load. Throughout testing, except during the recovery phase, pedal cadence was kept at $60 \mathrm{rpm}$. Electrocardiographic signs were monitored continuously. Transcutaneous oxygen saturation $\left(\mathrm{SpO}_{2}\right)$, heart rate $(\mathrm{HR})$ and perceived exertion were evaluated every one minute, while blood pressure (BP) was measured every two minutes.

The respiratory inductive plethysmography (Respitrace ${ }^{\circledR}$ 204, NIMS, Miami, FL, USA) was used to assess TAM during the incremental exercise tests. The accuracy of the plethysmography has been evaluated in patients with COPD at rest and during exercise $(24,25)$. This noninvasive system consists of two bands (Teflon ${ }^{\circledR}$-coated inductance) used to measure the changes in cross-sectional area of the RC and AB. Signals were calibrated using the Qualitative Diagnostic Calibration (26) and the following variables were analyzed:

1- Phase Angle (PhAng): it reflects the delay between $\mathrm{RC}$ and $\mathrm{AB}$ excursions and has been studied in patients with $\operatorname{COPD}(5,7,8)$. It ranges from $0^{\circ}$ (perfect synchrony) to $180^{\circ}$ (paradoxical movement) (26). This variable has the advantage of incorporating data from the whole respiratory cycle, but in the presence of irregular or "8 figure" Konno-Mead loops, PhAng values may be wrong (27).

2- Inspiratory Phase Relation (PhRIB) and Expiratory Phase Relation (PhREB): express the percentage of agreement between $\mathrm{RC}$ and $\mathrm{AB}$ movements directions during inspiratory or expiratory time, respectively. Range from $0 \%$ (perfect synchrony) to $100 \%$ (paradoxical movement). These parameters have the advantage of quantifying thoracoabdominal asynchrony at each point of the respiratory cycle and of not depending on calculations derived from Konno-Mead loops (26).

3- Cross-Correlation Function (CCF): it determines the delay in seconds ( $\mathrm{s}$ ) between the signals of $\mathrm{RC}$ and $\mathrm{AB}$ at each respiratory cycle. $\mathrm{CCF}$ equal 0 s reflects perfect thoracoabdominal synchrony (28). Its calculation does not depend on Konno-Mead loops $(28,29)$.

\section{Intervention}

Patients underwent a 12-week exercise training, three times per week, on a cycle ergometer at $70 \%$ (16) - target load - of the mean peak loads achieved in baseline tests. The goal was to reach 30 minutes of cycling at this intensity. Pedal frequency was maintained at $60 \mathrm{rpm} . \mathrm{SpO}_{2}$, BP, HR and perceived exertion were evaluated every five minutes. Recovery intervals where the workload was decreased to the basal load were allowed, according to participant tolerance or occurrence of any exercise interruption criterion (23).

\section{Data reduction}

The peak work load was defined as the last load at which the participant was able to complete at least 20s of pedaling. Plethysmography data processing was made by a blinded investigator for the 
study phase. In each evaluation, the following periods were considered: 1 ) at rest - 30s during steady state; 2) same load - the last 30s of the highest load tolerated for one minute in all baseline tests (19); 3) peak load - the last minute before peak load of each assessment.

Respiratory cycles with loops in "8 figure" were excluded from PhAng analysis (26). In order to decrease data variability, PhRIB and PhREB were submitted to angle transformation for the data analysis.

\section{Data analysis}

Comparisons of TAM among rest and the two levels of exercise (same load and peak load) were performed using ANOVA for repeated measures. Comparisons of TAM between baseline and intervention phases at two levels of exercise (same load and peak load) were carried out using three methods: Two Standard Deviation Band and Celeration Line tests (30, 31), and Visual Analysis, performed by three independent and blinded investigators. For assessing the concordance between assessors (30), Kappa statistics was used (32). It was considered as response to intervention results with concordance between Visual Analysis and at least one statistical test.

For statistical tests, the level of significance was set at $\alpha=0.05$. For ANOVA, Bonferroni correction was used, modifying the level of significance to 0.017 (33). Kappa statistics and ANOVA were performed using the Statistical Package for the Social Sciences (SPSS 13.0, Chicago, IL, USA). Data are present as mean \pm standard deviation when appropriate.

\section{Results}

Table 1 shows the spirometric and anthropometric data for the two participants.

Figure 1 (panel I) presents a typical example of waveforms at rest (A) and during exercise (B) seen through the software (RespEvents, NIMS, USA). At rest, the TAM can be considered almost synchronic, with delay occurring between thoracic and abdominal compartments only in some respiratory cycles (indicated by dotted lines). During exercise, in addition to the delay between compartments, it can be observed asynchrony within the cycles (indicated by arrows). It was also observed that tidal volume waveform during exercise was non-sinusoidal and irregularities appear to be arising out of the abdominal compartment. Similar waveforms were observed in both participants in all tests. The bottom of Figure 1 (panel II) shows examples of Konno-Mead loops with (a, b and c) and without (d) "8 figure".

Table 2 presents TAM data at rest and during exercise. Comparisons showed significant increases in PhRIB, PhREB and CCF during exercise, in both participants, without significant differences between the two levels of exercise.

Figure 2 presents charts of TAM variables throughout the study phases at same load and peak load which were used as the basis for Visual Analysis. Phase Angle was not analyzed due to the high number of respiratory cycles presenting Konno-Mead loops with "8 figure", particularly during exercise.

Phase Angle was not analyzed due to the high number of respiratory cycles presenting Konno-Mead loops with "8 figure", particularly during exercise.

Table 1 - Spirometric and anthropometric data for the two participants

\begin{tabular}{lcc}
\hline Variables & Participant 1 & Participant 2 \\
\hline \multicolumn{1}{c}{ Spirometric } & & 38.00 \\
FEV $_{1}(\%$ of predicted) * & 38.00 & 50.76 \\
FEV $_{1} /$ FVC (\%) * & 48.28 & Man \\
Anthropometric & & 64 \\
Sex & Man & 55.10 \\
Age (years) & 73 &
\end{tabular}


Table 1 - Spirometric and anthropometric data for the two participants

(Conclusion)

\begin{tabular}{lcc}
\hline Variables & Participant 1 & Participant 2 \\
\hline Height $(\mathrm{m})$ & 1.63 & 1.65 \\
$\mathrm{BMl}\left(\mathrm{kg} / \mathrm{m}^{2}\right)$ & 22.39 & 20.20 \\
\hline
\end{tabular}

Source: Research data.

Notes: $\mathrm{FEV}_{1}=$ forced expiratory volume in first second; FVC = forced vital capacity; ${ }^{*}=$ according to Pereira (39), BMI = body mass index; HAP $=$ Human Active Profile; MRC $=$ Medical Research Council. When appropriated, data are reported as mean \pm standard deviation.

I

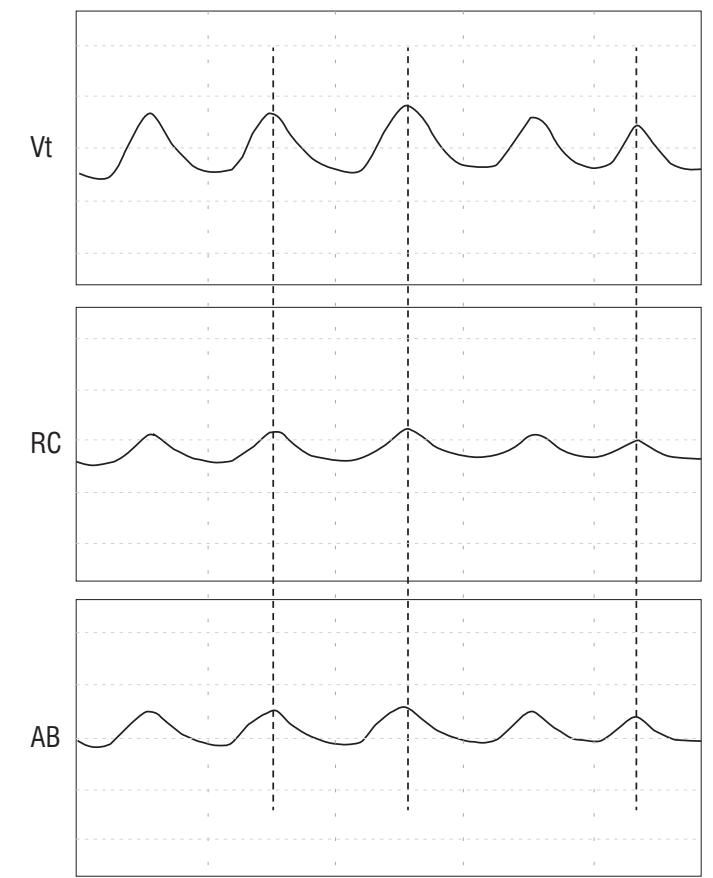

B
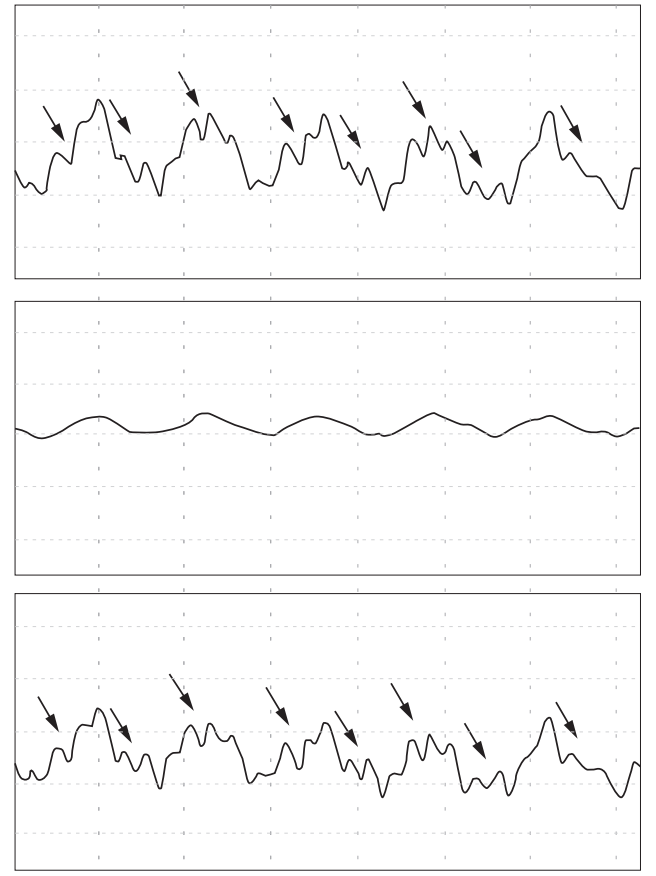

II

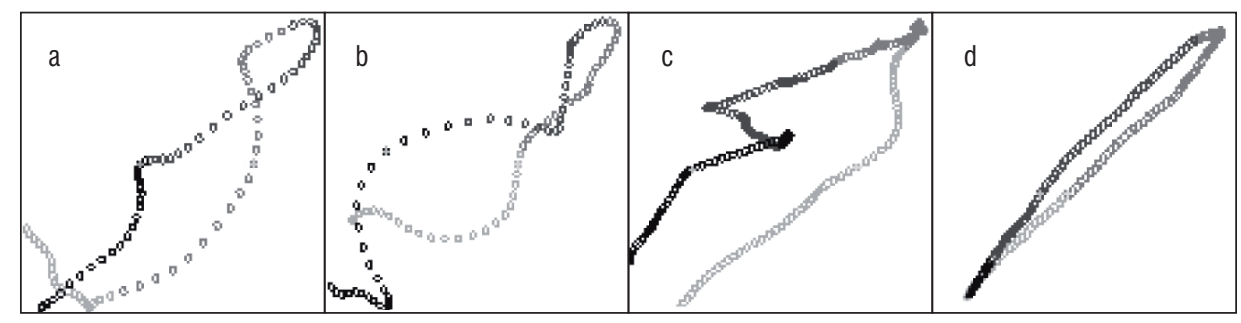

Figure 1 - Example of typical waveforms at rest (A) and during exercise (B) on panel I, and Konno-Mead loops with "8 figure" (a, b and c) and without "8 figure" (d) on panel II

Source: Research data.

Notes: $\mathrm{Vt}=$ Tidal Volume; $\mathrm{RC}=$ Rib Cage; $\mathrm{AB}=$ Abdomen. The dotted line allows to verify the compartments delay. The arrows indicate the irregularities waves. 
Table 2 - All tests mean of asynchronous TAM data at rest and during two exercise levels (same load and peak load) for both participants

\begin{tabular}{lccc}
\hline Variables & Rest & Same load & Peak load \\
\hline Participant 1 & & & \\
PhRIB (\%) & $7.10 \pm 2.54$ & $19.57 \pm 5.06^{\star}$ & $22.81 \pm 3.80^{\star}$ \\
PhREB (\%) & $3.14 \pm 1.54$ & $17.16 \pm 4.96^{\star}$ & $14.88 \pm 3.37^{\star}$ \\
CCF (s) & $0.02 \pm 0.01$ & $0.10 \pm 0.04^{*}$ & $0.12 \pm 0.03^{\star}$ \\
\hline Participant 2 & & \\
PhRIB (\%) & $5.12 \pm 1.25$ & $13.36 \pm 3.69^{*}$ & $17.22 \pm 3.03^{\star}$ \\
PhREB (\%) & $4.56 \pm 1.89$ & $9.49 \pm 5.10^{\star}$ & $11.18 \pm 5.37^{\star}$ \\
CCF (s) & $0.01 \pm 0.02$ & $0.10 \pm 0.03^{*}$ & $0.09 \pm 0.03^{\star}$ \\
\hline
\end{tabular}

Source: Research data.

Notes: Data are presented as mean \pm standard deviation. PhRIB $=$ inspiratory phase relation; PhREB $=$ expiratory phase relation; $\mathrm{CCF}=$ cross-correlation function; * = statistical significant difference between rest and the two levels of exercise, considering significant $p<0.017$, according to Bonferroni's correction.

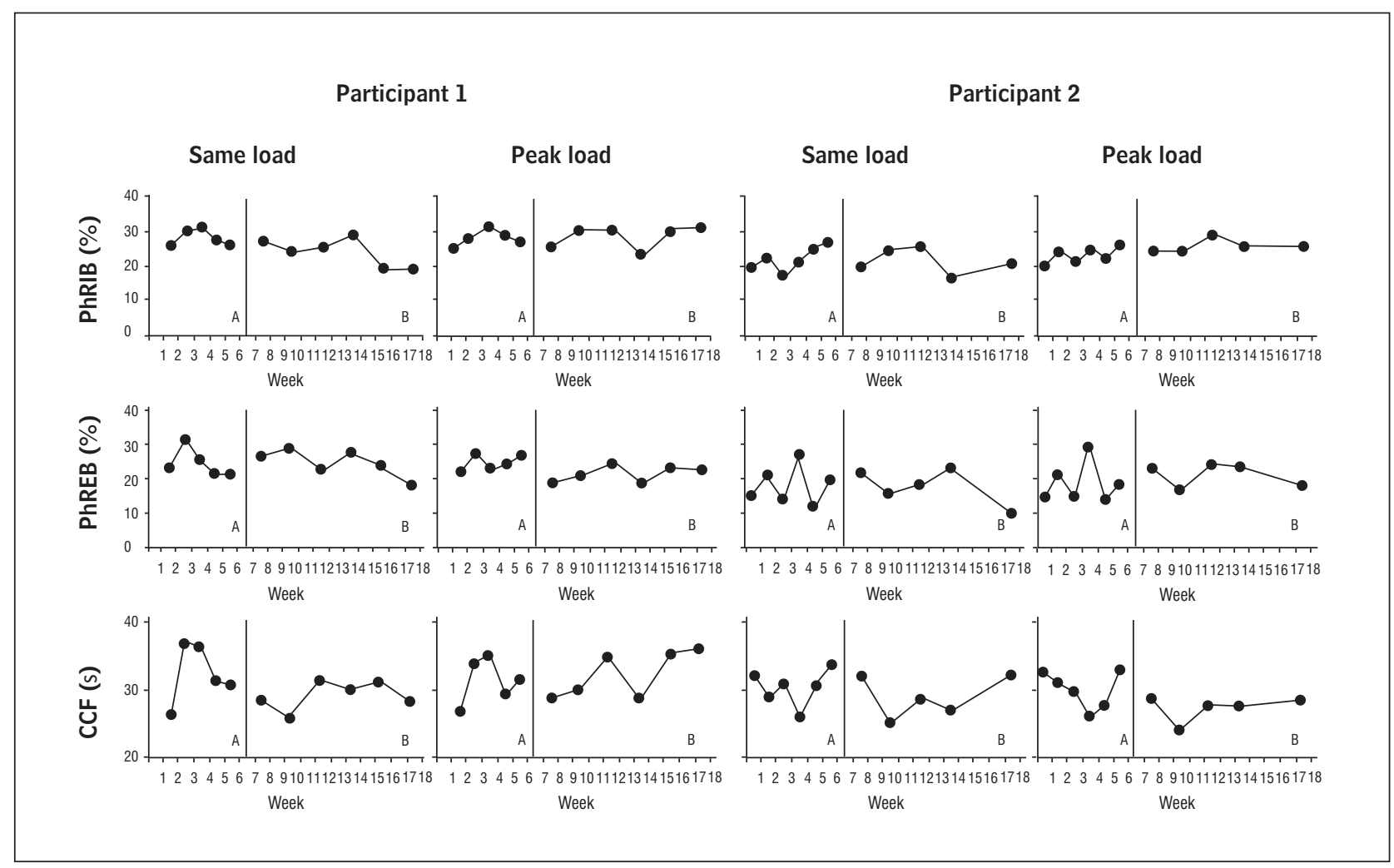

Figure 2 - Graphics of TAM variables during baseline (A) and intervention (B) phases at rest, same load and peak loak on the two participants studied

Source: Research data.

Notes: PhRIB $=$ inspiratory phase relation in percentage; $\mathrm{PhREB}=$ expiratory phase relation in percentage; $\mathrm{CCF}=$ cross-correlation function in seconds; $A$ = baseline phase with periodic assessments weekly during six weeks; $B=$ intervention phase with periodic assessments each 15 days, during 12 weeks. 
Table 3 presents the results regarding Visual Analysis, Celeration Line and Two Standard Deviation Band, and the response to intervention of each variable at same load and peak load. Participant 1 showed significant decrease in PhRIB at same load and in PhREB at peak load, without significant differences in other variables. Participant 2 showed a significant decrease in PhRIB and PhREB at same load and in PhRIB at peak load. No significant changes were observed in other variables. With respect to Visual Analysis, it was observed almost perfect agreement (Kappa from 0.81 to 1.00) between two of the three examiners for most variables and for only one variable there was substantial agreement (Kappa from 0.61 to 0.80 ) (31).

Table 3 presents the results regarding Visual Analysis, Celeration Line and Two Standard Deviation Band, and the response to intervention of each variable at same load and peak load. Participant 1 showed significant decrease in PhRIB at same load and in PhREB at peak load, without significant differences in other variables. Participant 2 showed a significant decrease in PhRIB and PhREB at same load and in PhRIB at peak load. No significant changes were observed in other variables. With respect to Visual Analysis, it was observed almost perfect agreement (Kappa from 0.81 to 1.00) between two of the three examiners for most variables and for only one variable there was substantial agreement (Kappa from 0.61 to 0.80 ) (31).

\section{Discussion}

The main results of this study were: 1) Comparisons of TAM between baseline and intervention phase showed significant decrease in thoracoabdominal asynchrony at same load and peak load; 2) Comparisons between rest and exercise showed significant increase in asynchronous TAM at same load and peak load, without significant differences between these two levels of exercise.

To the best of our knowledge, this study was the first one to assess the impact of a lower-limb endurance training program on variables that reflect thoracoabdominal asynchrony during exercise in COPD patients. Comparisons of TAM variables between baseline and training phase showed significant decrease in thoracoabdominal asynchrony at two levels of exercise. This reduction can be considered as a positive impact of endurance training, since the presence of asynchronous TAM in patients with COPD has been associated with higher severity of the disease, increased risk of respiratory failure and worse prognosis (1-3).

Table 3 - Response to intervention according to Visual Analysis, Celeration Line and Two Standard Deviation Band during same load and peak load

\begin{tabular}{|c|c|c|c|c|c|c|}
\hline \multirow[b]{2}{*}{ Methods } & \multicolumn{3}{|c|}{ Participant 1} & \multicolumn{3}{|c|}{ Participant 2} \\
\hline & PhRIB (\%) & PhREB (\%) & CCF (s) & PhRIB (\%) & PhREB (\%) & $\operatorname{CCF}(s)$ \\
\hline $\begin{array}{l}\text { Same load } \\
\text { response }\end{array}$ & $\downarrow^{*}$ & --- & --- & $\downarrow^{*}$ & $\downarrow^{*}$ & --- \\
\hline VA & $\downarrow$ & --- & --- & $\downarrow$ & $\downarrow$ & --- \\
\hline$C L$ & ns & $\uparrow^{*}$ & ns & $\downarrow^{*}$ & $\downarrow^{*}$ & ns \\
\hline TSDB & $\downarrow^{*}$ & ns & ns & ns & ns & ns \\
\hline $\begin{array}{l}\text { Peak load } \\
\text { response }\end{array}$ & --- & $\downarrow^{*}$ & --- & $\downarrow^{*}$ & --- & --- \\
\hline VA & --- & $\downarrow$ & --- & $\downarrow$ & --- & $\downarrow$ \\
\hline $\mathrm{CL}$ & $\downarrow^{*}$ & $\downarrow^{*}$ & ns & $\downarrow^{*}$ & ns & $\uparrow^{*}$ \\
\hline TSDB & ns & ns & ns & ns & ns & ns \\
\hline
\end{tabular}

Source: Research data.

Notes: VA = Visual Analysis; $\mathrm{CL}=$ Celeration Line; TSDB = Two Standard Deviation Band, PhRIB = phase inspiratory relation; PhREB = phase expiratory relation; CCF $=$ cross-correlation function, $---=$ without change, $\downarrow=$ decrease, $\uparrow=$ increase, ${ }^{*}=$ statistical significance, considering $p<0.05$. 
However, it was observed that TAM variables responses were not the same for the participants evaluated. This difference could be the result of distinct dynamic hyperinflation patterns, as reported in the literature $(21,34-37)$, since respiratory muscles dysfunction, related to lung hyperinflation, has been described as the main factor responsible for thoracoabdominal asynchrony in patients with COPD $(5,8,36-38)$. However, it cannot be confirmed as dynamic hyperinflation was not assessed in this study. Different thoracoabdominal asynchrony patterns $(1,9)$ and progression of these patterns during exercise in some patients with COPD (9) may also have contributed to this difference between the participants.

Comparisons between rest and the two levels of exercise showed significant increase in asynchronous TAM at same load and peak load, without significant differences between these exercise levels. This result is similar to that observed by Alves et al. (7), who compared the TAM of 22 COPD patients at rest and during three levels of progressive exercise (30-50\%, $70-80 \%$ and $100 \%$ of the peak work load) performed on a cycle ergometer. These authors observed significant increase in asynchronous TAM during all exercise levels, without difference between them.

During exercise, non-sinusoidal waves were observed, showing irregularities from abdominal compartment. This finding was observed in both participants. Similar waves have been observed in COPD patients during spontaneous breathing $(1,10)$ and exercise $(9,38)$. Ashutosh et al. $(1)$ assessed TAM during spontaneous breathing at rest in 16 stable patients and in 14 patients with exacerbation. Asynchronous TAM was observed in 13 patients, 1 stable and 12 exacerbated. Three types of thoracoabdominal asynchrony were observed, all involving abdominal compartment irregularities. Delgado et al. (9) observed, during progressive exercise on a treadmill, similar movements of $\mathrm{RC}$ among patients but distinct $\mathrm{AB}$ movement patterns. It was also found that asynchronous TAM was related to underlying pulmonary abnormality and exercise limitation.

Regarding TAM asynchrony at rest, studies presenting PhRIB, PhREB and CCF values in patients with COPD have not been found. PhAng is the TAM variable most often reported in these patients $(5,7,8)$. It was observed a large variability in PhAng mean values among these studies and important variability among subjects of each study, which can be verified by the standard deviation values. This variability may be due to the analysis of respiratory cycles based on altered Konno-Mead loops since those authors did not report the exclusion of "8 figure" Konno-Mead loops during PhAng analysis. Thus, a rigorous assessment of Konno-Mead loops with exclusion of "8 figures" is an important step to be followed in PhAng calculation. In the present study, the large number of "8 figure" Konno-Mead loops was determinant for the exclusion of this variable from data analysis.

Both participants studied increased their peak exercise capacity at the end of 12 weeks of training. It may be evidenced by the increase in the work load reached in the last incremental test when compared to mean peak load of baseline tests: 17 and 10 watts in participants 1 and 2, respectively. These values are in agreement with results observed in previous studies $(17,19,21)$ and may be related to the improvement of the physical performance provided by the lower-limb endurance training program.

\section{Conclusion}

Using a single-subject experimental design, the effects of a lower-limb endurance training program on variables reflecting thoracoabdominal motion were evaluated in two patients with severe COPD. The results suggest that despite the exercise augmented the asynchrony compared to rest, the endurance training program influenced positively the thoracoabdominal motion leading to significant decrease in asynchrony during exercise in patients assessed.

\section{Funding acknowledgements}

This work was partially supported by FAPEMIG [grant number CDS APQ-5350 5.01/07]; CNPq [grant number 555083/2008-0] and Capes [Danielle C. França scholarship].

\section{References}

1. Ashutosh K, Gilbert R, Auchincloss JH Junior, Peppi D. Asynchronous breathing movements in patients with chronic obstructive pulmonary disease. Chest. 1975;67(5):553-7. doi:10.1378/chest.67.5.553. 
2. Capria ME, D'Negri C, De Vito EL. Relationship between Hoover sign, functional and variables, and curvature radius in patients with obstructive pulmonary disease. Medicina (B Aires). 2003;63(5):369-76.

3. Garcia-Pachon E, Padilla-Navas I. Frequency of Hoover's sign in stable patients with chronic obstructive pulmonary disease. Int J Clin Pract. 2006;60(5):514-7. doi:10.1111/j.1368-5031.2006.00850.x.

4. Global Strategy for the Diagnosis, Management, and Prevention of Chronic Obstructive Pulmonary Disease - GOLD. Global strategy for the diagnosis management, and prevention of COPD. 2007. Available at: http://www.goldcopd.org.

5. Sackner MA, Gonzalez H, Rodriguez M, Belsito A, Sackner DR, Grenvik S. Assessment of asynchronous and paradoxic motion between rib cage and abdomen in normal subjects and in patients with chronic obstructive pulmonary disease. Am Rev Respir Dis. 1984;130(4):588-93. PMid:6486558.

6. Tobin MJ, Perez W, Guenther SM, Lodato RF, Dantzker DR. Does rib cage-abdominal paradox signify respiratory muscle fatigue? J Appl Physiol. 1987;63(2):85160. PMid:3654445.

7. Alves GS, Britto RR, Campos FC, Vilaça AB, Moraes KS, Parreira VF. Breathing pattern and thoracoabdominal motion during exercise in chronic obstructive pulmonary disease. Braz J Med Biol Res. 2008;41(11):94550. doi:10.1590/S0100-879X2008001100001.

8. Bloch KE, Li Y, Zhang J, Bingisser R, Kaplan V, Weder $\mathrm{W}$, et al. Effect of surgical lung volume reduction on breathing patterns in severe pulmonary emphysema. Am J Respir Crit Care Med. 1997;156(2):553-60. PMid:9279239.

9. Delgado HR, Braun SR, Skatrud JB, Reddan WG, Pegelow DF. Chest wall and abdominal motion during exercise in patients with chronic obstructive pulmonary disease. Am Rev Respir Dis. 1982;126(2):200-5. PMid:7103243.

10. Tobin MJ, Chadha TS, Jenouri G, Birch SJ, Gazeroglu HB, Sackner MA. Breathing patterns. 2. Diseased Subjects. Chest. 1983;84(3):286-94. doi:10.1378/ chest.84.3.286.

11. Rochester CL. Exercise training in chronic obstructive pulmonary disease. J Rehabil Res. 2003;40(5 Suppl 2): 59-80. doi:10.1682/JRRD.2003.10.0059.
12. Nici L, Donner C, Wouters E, Zuwallack R, Ambrosino N, Borbeau J, et al. on behalf of the ATS/ERS Group. American Thoracic Society/European Respiratory Society statement on pulmonary rehabilitation. Am J Respir Crit Care Med. 2006;173(12):1390-413. doi:10.1164/rccm.200508-1211ST.

13. Ferguson GT. Why does the lung hyperinflate? Proc Am Thorac Soc. 2006;3(2):176-9. doi:10.1513/pats. 200508-094DO.

14. MacIntyre NR. Muscle dysfunction associated with chronic obstructive pulmonary disease. Respir Care. 2006;51(8):840-7. PMid:16867196.

15. O’Donnell DE, Revill SM, Webb KA. Dynamic hyperinflation and exercise intolerance in chronic obstructive pulmonary disease. Am J Respir Crit Care Med. 2001;164(5):770-7. PMid:11549531.

16. Ortega F, Toral J, Cejudo P, Villagomez R, Sanchez H, Castillo J, et al. Comparison of effects of strength and endurance training in patients with chronic obstructive pulmonary disease. Am J Respir Crit Care Med. 2002;166(5):669-74. doi:10.1164/rccm.2107081.

17. Mador MJ, Bozkanat E, Aggarwal A, Shaffer M, Kufel TJ. Endurance and strength training in patients with COPD. Chest. 2004;125(6):2036-45. doi:10.1378/ chest.125.6.2036.

18. Pulmonary rehabilitation-1999. American Thoracic Society. Am J Respir Crit Care Med.1999;159(5):166682. PMid:10228143.

19. Porszasz J, Emtner M, Goto S, Somfay A, Whipp BJ, Casaburi R. Exercise training decreases ventilatory requirements and exercise-induced hyperinflation at submaximal intensities in patients with COPD. Chest. 2005;128(4):2025-34. doi:10.1378/ chest.128.4.2025.

20. Ong KC, Chong WF, Soh C, Earnest A. Comparison of different exercise tests in assessing outcomes of pulmonary rehabilitation. Respir Care. 2004;49(12):14981503. PMid:15571640.

21. Georgiadou O, Vogiatzis I, Stratakos G, Koutsoukou A, Golemati S, Aliverti A, et al. Effects of rehabilitation on chest wall volume regulation during exercise in COPD patients. Eur Respir J. 2007;29(2):284-91. doi:10.1183/09031936.00121006. 
22. Standards for the diagnosis and care of patients with chronic obstructive pulmonary disease. American Thoracic Society. Am J Respir Crit Care Med. 1995;152(5):S77-S121. PMid:7582322.

23. ATS/ACCP Statement on cardiopulmonary exercise testing. Am J Respir Crit Care Med. 2003;167(2):211277. doi:10.1164/rccm.167.2.211.

24. Tobin MJ, Jenouri G, Lind B, Watson H, Schneider A, Sackner MA. Validation of respiratory inductive plethysmography in patients with pulmonary disease. Chest. 1983;83(4):615-20. doi:10.1378/ chest.83.4.615.

25. Clarenbach CF, Senn O, Brack T, Kohler M, Bloch KE. Monitoring of ventilation during exercise by a portable respiratory inductive plethysmograph. Chest. 2005;128(3):1282-90. doi:10.1378/chest.128.3.1282.

26. Nims INC. RespEvents: operations manual for health care practitioners. 2001. [cited 2012 Dec. 18]. Available at: http://www.nims-inc.com.

27. Beydon N, Davis SD, Lombardi E, Allen JL, Arets HG, Aurora P, et al. An official American Thoracic Society/ European Respiratory Society statement: pulmonary function testing in preschool children. Am J Respir Crit Care Med. 2007;175(12):1304-45. doi:10.1164/ rccm.200605-642ST.

28. Millard RK. Inductive plethysmography components analysis and improved non-invasive postoperative apnoea monitoring. Physiol Meas. 1999;20(2):175-86. doi:10.1088/0967-3334/20/2/307.

29. Black AMS, Millard RK. Assessing thoracoabdominal asynchrony: short communication. J Clin Psychol. 2000;21(3):383-5. doi:10.1046/j. 1365- 2281.2001.00325.x.

30. Portney LG, Watkins MP. Single subject designs. In: Portney LG, Watkins MP, editors. Foundations of clinical research: applications to practice. Vol. 2. New Jersey: Prentice-Hall; 2000. p. 223-64.

31. Landis JR, Koch GG. The measurement of observer agreement for categorical data. Biometrics. 1977; 33(1):159-74. doi:10.2307/2529310.

32. Ottenbacher K. Statistical analysis of syngle system. In: Ottenbacher K, editor. Evaluate clinical change: estrategies for occupational and physical therapists. Baltimore: Williams \& Wilkins; 1986. p. 166-95.
33. Munro BH. Differences among group means: one way analyses of variance. In: Munro BH, editor. Statistical methods for health care research. Philadelphia: Lippincott; 2000. p. 137-59.

34. Aliverti A, Stevenson N, Dellaca RL, Lo MA, Pedotti A, Calverley PM. Regional chest wall volumes during exercise in chronic obstructive pulmonary disease. Thorax. 2004;59(3):210-6. doi:10.1136/thorax. 2003.011494.

35. Vogiatzis I, Stratakos G, Athanasopoulos D, Georgiadou O, Golemati S, Koutsoukou A, et al. Chest wall volume regulation during exercise in COPD patients with GOLD stages II to IV. Eur Respir J. 2008;32(1):42-52. doi:10.1183/09031936.00155207.

36. Puente-Maestu L, Abad YM, Pedraza F, Sanchez G, Stringer WW. A controlled trial of the effects of leg training on breathing pattern and dynamic hyperinflation in severe COPD. Lung. 2006;184(3):159-67. doi:10.1007/s00408-005-2576-x.

37. Aliverti A, Quaranta M, Chakrabarti B, Albuquerque ALP, Calverle PM. Paradoxical movement of the lower ribcage at rest and during exercise in COPD patients. Eur Respir J. 2009:33(1):49-60. doi: 10.1183/09031936.00141607.

38. Gosselink R. Physical therapy in adults with respiratory disorders: where are we? Braz J Phys Ther. 2006;10(4):361-72.

39. Pereira CAC. Espirometria. J Pneumol. 2002;28 [suppl3]:S1-S82.
Received: 02/01/2012

Recebido: 01/02/2012

Approved: 09/06/2012 Aprovado: 06/09/2012 